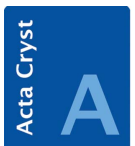

ISSN 2053-2733
FOUNDATIONS

ADVANCES
Keywords: Ewald Prize; International Union of Crystallography

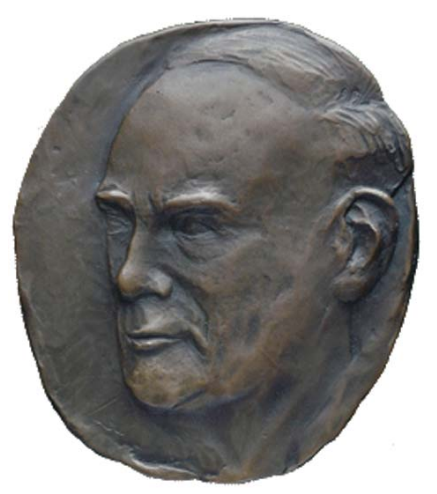

\section{Nominations for the Ewald Prize}

\author{
A. T. Ashcroft*
}

IUCr, 2 Abbey Square, Chester, CH1 2HU, UK. *Correspondence e-mail: execsec@iucr.org

The International Union of Crystallography (IUCr) is pleased to invite nominations for the Ewald Prize for outstanding contributions to the science of crystallography. The Prize is named after Professor Paul P. Ewald, in recognition of his significant contributions to the foundations of crystallography and to the founding of the International Union of Crystallography. Professor Ewald was the President of the Provisional International Crystallographic Committee from 1946 to 1948, the first Editor of the IUCr publication Acta Crystallographica from 1948 to 1959 and the President of the IUCr from 1960 to 1963.

The Prize consists of a medal, a certificate and a financial award, and is presented once every three years during the triennial International Congress of Crystallography. The recipients to date are as follows:

\begin{tabular}{lll}
\hline Year & Place & Recipient \\
\hline 1987 & Perth, Australia & Professor J. M. Cowley and Dr A. F. Moodie \\
1990 & Bordeaux, France & Professor B. K. Vainshtein \\
1993 & Beijing, China & Professor N. Kato \\
1996 & Seattle, USA & Professor M. G. Rossmann \\
1999 & Glasgow, UK & Professor G. N. Ramachandran \\
2002 & Geneva, Switzerland & Professor M. M. Woolfson \\
2005 & Florence, Italy & Professor P. Coppens \\
2008 & Osaka, Japan & Dr D. Sayre \\
2011 & Madrid, Spain & Professor E. Dodson, Professor C. Giacovazzo and Professor \\
& & G. M. Sheldrick \\
2014 & Montreal, Canada & Professor A. Janner and Professor T. W. J. M. Janssen \\
2017 & Hyderabad, India & Professor T. L. Blundell \\
\hline
\end{tabular}

The twelfth Prize, for which nominations are now being invited, will be presented at the Prague Congress in August 2020.

Scientists who have made contributions of exceptional distinction to the science of crystallography are eligible for the Ewald Prize, irrespective of gender, nationality, age or experience. The Selection Committee will give careful attention to the nominations of outstanding scientists who have not yet won a Nobel Prize. Either an exceptionally distinguished scientific career or a major scientific accomplishment may be recognized. Current members of the Selection Committee and the President of the IUCr are not eligible. No restrictions are placed on the time or the means of publication of the nominee's contributions. The Prize may be shared by more than one contributor, but not more than three, to the same scientific achievement.

Nominations for the Ewald Prize should be submitted electronically, using the Ewald Prize Nomination Form, to the Executive Secretary of the International Union of Crystallography (execsec@iucr.org), from whom copies of the Nomination Form and the names of the Selection Committee may be obtained (these can also be found at https:// www.iucr.org/iucr/ewald-prize). The closing date for nominations is 31 August 2019. 